\title{
MATERNO-FETAL LACTIC ACID MEDIATED INFUSION ACIDOSIS. NOT FACT BUT FICTION.
}

\begin{abstract}
DELlENBACH P.*, PIQUARD F.**, SCHAEFER A.**, HSIUNG $\mathrm{R}^{*}$ and HABEREY P. **
\end{abstract}

Determinations of acid-base parameters in perinatology frequently have shown particular instances' where the newborn has a low $\mathrm{pH}$ but a normal Apgar score immediately after delivery. It has been proposed that this acidosis could be due to transplacental infusion of lactic acid from the mother. The origin of this high level of maternal lactate may relate to pain, hyperventilation and bearing down efforts associated with difficult labour. In what classically is called "infusion acidosis", maternal lactic acid then crosses over the placenta towards the fetus. The accepted criterion for this type of fetal and neonatal acidosis is a positive delta materno-fetal base deficit for extracellular fluid. In the absence of a practical and exact method for the routine determination of lactate in both motherr and fetus during labour and at the time of birth, this assumption has seldom been challenged.

We have been able to propose a method of evaluation which will give instantaneous, exact results for plasma or whole blood lactate on micro samples collected at any time during labour on the fetal scalp, at birth on cord blood, arterial and venous, or from the mother (2).

In a first study we measured lactate at term of 60 normal pregancies, maternal and fetal blood being obtained at cesarean section prior to the onset of labour.

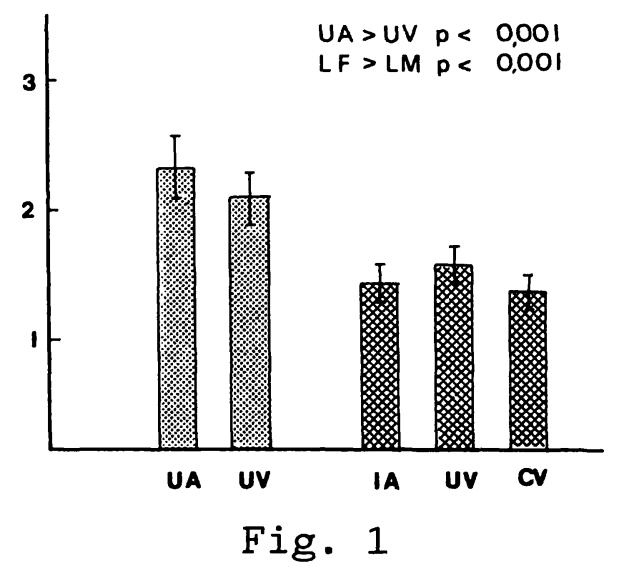

Fig 1 illustrates the mean values of lactate in these 60 cases. Lactate level is the highest in the umbilical artery, the values in the vein being invariably lower. Fetal values, either arterial or venous, are invariably ( $p<0,001$ ) higher than maternal ones. This confirms on a much larger scale that the human fetus is not a lactate consumer but a lactate producer (SCHNEIDER 3).

In a second series of studies we measured maternal and fetal lactate

throughout normal and pathological labour in 230 cases. We observed a moderate increase (up to $4 \mathrm{mmol}^{-1}$ ) in maternal as well as fetal lactate overtime during the second stage of labour ; fetal lactate rose to high and dangerous ( $>6 \mathrm{mmol} . \mathrm{L}^{-1}$ ) levels 
in case of hypoxia and seemed better correlated with the clinical state of the fetus than any other parameter.

We also noticed that whatever the level of lactate in the mother, the values in the umbilical artery were invariably higher than in the vein.

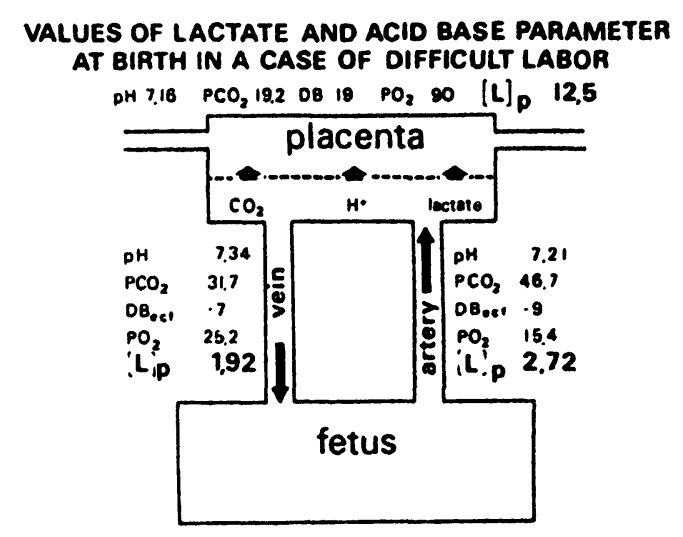

Fig. 2

Fig 2 presents a case where the mother was very agitated throughout her labour and her lactate rose to $12,5 \mathrm{mmol} . \mathrm{L}^{-1}$ by the end of the second stage. Despite these very high values in the mother umbilical arterial values were higher $(2,72)$ than venous ones $(1,92)$.

We have been lead to the thought that in the human, feto-maternal transfer of lactate is not regulated solely by a concentration gradient. Lactic acid mediated infusion acidosis thus might not be fact but fiction. A satisfactory explanation to this surprising and at this time controversial finding, can be proposed if one assumes that in hemochorial placenta of human the transfer mechanism of lactate could be the same as the one described by MOLL (1) for the guinea pig hemochorial placenta, i.e., facilitated diffusion coupled with a proton $[\mathrm{H}]^{+}$. The usual trend for transfer of lactate will therefore be from the fetus (low $\mathrm{pH} / \mathrm{high}$ proton level) to the mother (high $\mathrm{pH} /$ low proton level).

It thus appears that an abnormally high level of lactate in the fetus or newborn would represent a very specific marker of oxygen lack during child birth. Lactate should therefore become an important parameter in perinatal acid-base studies.

\section{Bibliography}

1. MOLL W., GIRARD H., GROS G. : Facilitated diffusion of lactic acid in the guinea-pig placenta. Pflügers Arch., 1980, 385, 229-238.

2. PIQUARD F., SCHAEFER A., DELLENBACH P., HABEREY P. : Rapid bedside estimation of plasma and whole blood lactic acid. Intensive Care Med., 1980, 7, 35-38.

3. SCHNEIDER H., CHALLIER J.C., DANCIS J. : Transfer and metabolism of glucose and lactate in the human placenta studied by a perfusion system in vitro. Placenta (suppl. 2) 1981, 129-138.

* Centre Médico-Chirurgical et Obstétrical de la Sécurité Sociale 19, rue Louis Pasteur SCHILTIGHEIM 67042 STRASBOURG Cédex France 